\title{
Encapsulation of PCM for Thermo-Regulating Fabric Application
}

\author{
Subhas Ghosh, Prasad Bhatkhande \\ College of Technology, Eastern Michigan University, Ypsilanti, USA \\ Email: sghosh@emich.edu
}

Received August 14, 2012; revised September 17, 2012; accepted September 25, 2012

\begin{abstract}
Polyethylene glycol (PEG) has been used as a phase change material (PCM) to create a thermo-regulating fabric. PEG-600 (Mw) was encapsulated using an in-situ polymerization technique in an oil-in water emulsion with encapsulating water-immiscible liquid by the reaction of urea with formaldehyde at acidic $\mathrm{pH}$. Both FTIR analysis and DSC studies verified the formation of PEG microcapsules (MC). Melting temperature (Tm) of the microcapsules was found approximately $21^{\circ} \mathrm{C}$ which was the same as neat PEG. The heat storage capacity of these MCs was determined to be $12.78 \mathrm{~J} / \mathrm{g}$ by DSC analysis. FTIR analysis of the MCs exhibited the peaks at $3211 \mathrm{~cm}^{-1}, 1650 \mathrm{~cm}^{-1}$, and $1400 \mathrm{~cm}^{-1}$. These are the characteristic absorption peaks of $-\mathrm{NH}_{2},-\mathrm{C}=\mathrm{O}$ stretching and $-\mathrm{CH}$ bending vibrations, respectively. Fabric coated with PEG microcapsules showed a $20 \%$ higher thermal resistance, than the uncoated fabric, when heated on a Sweating Hot Plate (MTNW Corporation).
\end{abstract}

Keywords: Phase Change Material; Micro-Encapsulation; PEG

\section{Introduction}

In the context of textiles and clothing, wear comfort is the state in which we are unaware of the clothing we are wearing. Comfort may be classified into four main categories: thermal or thermo physiological comfort, sensorial comfort, garment fit, and psychological comfort [1]. The thermal factor is the most decisive one affecting the comfort level [2]. This article is associated with the study of Phase Change Material (PCM) that can regulate thermal energy in a too warm or too cold situation. Materials that undergo the process of phase change are known as PCM. These materials give off heat as they change from a liquid state to a solid state and absorb heat as they return to a liquid state.

PCMs have been applied to textiles in a variety of processes such as coating, lamination, finishing, melt spinning, bi-component synthetic fiber extrusion, injection molding, encapsulation, etc. Microcapsule production may be achieved by means of physical or chemical techniques. These have been limited by the high cost of processing, regulatory affairs, and the use of organic solvents; which are a concern for health and the environment. Physical methods are mainly spray drying or centrifugal and fluidized bed processes, which are inherently incapable of producing microcapsules smaller than $100 \mu \mathrm{m}$ [3]. In situ polymerization generally involves bringing together two immiscible liquids, such as water and organic solvent, containing complimentary, directacting, organic intermediates that will react with each other to establish a solid pre-condensate [4]. In this investigation our objective was to develop an in situ polymerization technique to create PEG microcapsules that can be applied to different textile fabrics. Microencapsulation is a technique by which solid, liquid or gaseous active ingredients are packaged within a second material for the purpose of shielding the active ingredient from the surrounding environment. Thus the active ingredient is designated as the core material whereas the surrounding material forms the shell. This technique has been employed in a diverse range of fields from chemicals and pharmaceuticals to cosmetics and printing.

Microencapsulation technology was utilized in the early 1980s by the US National Aeronautics and Space Administration (NASA) with the aim of managing the thermal barrier properties of space suits. The microcapsules have walls less than $1 \mu \mathrm{m}$ thick and are typically 20 - $40 \mu \mathrm{m}$ in diameter, with a PCM loading of $80 \%-85 \%$. The small capsule size provides a relatively large surface area for heat transfer. The rate at which the PCM reacts to an external temperature change is very rapid [5]. The thermal properties of a microcapsule are influenced by three factors: mean diameter, expansion during the phase change process, and shell's chemical structure [6]. Brown et al. reported the effect of process parameters and chemicals used on microcapsule characteristics during 
synthesis. The average microcapsule diameter is controlled by the agitation rate where the relationship between the average diameter and the agitation rate is linear in $\log$-log scale. This is due to the dependence between droplet size and shear rate. Excess ammonium chloride or resorcinol, the addition of smaller volumes of Dicyclopentadiene (DCPD), contaminated glassware, an unbalanced or unaligned mixer, and lower initial $\mathrm{pH}$ dramatically increase the thickness of the outer permeable layer [4].

\section{Experimental}

\subsection{Materials}

Polyethylene glycol (PEG), having 600 molecular weight (Mw), was used as a PCM that was obtained from Polysciences. The repeating unit of PEG is oxyethylene (-O$\mathrm{CH} 2-\mathrm{CH} 2-)$ n, with either side of the chain comprising of hydroxyl groups. The other chemicals used were Sodium salt of dodecyl benzene sulfonic acid (SDS), Urea, Polyvinyl Alcohol (PVA), Formaldehyde, Triton X100, Ammonium Chloride, Acetone, and 1,3-Benzenediol (Resorcinol) and Sodium carbonate. All chemicals were obtained from Sigma Aldrich Chemicals Co. Ltd. and used without further purification.

\subsection{Analytical Methods}

A Q200 Differential Scanning Calorimeter (DSC) from TA Instruments was used to study the thermal behavior of the microcapsules. A Bruker (Tensor 27) Fourier Transform Infrared Spectrometer (FTIR) was used to detect the presence of PEG in the microcapsules. A S-3400 N model Scanning Electron Microscope (SEM) was used to determine the shape and size of the microcapsules. Thermal effectiveness of the microcapsule coated fabric was examined using a Sweating Hot Plate (serial number 223-21) from MTNW incorporation. The hot plate was placed inside a TPS Lunaire Climatic Chamber (Model No. CEO 910-4) according to ASTM F 1868-02.

\subsection{Encapsulation Procedure}

A unique encapsulation procedure was developed by modifying the methods used by Taboada et al. and Rochmadi et al. [7,8]. A mixture of PEG-600 and DI water was prepared in a $250 \mathrm{ml}$ glass beaker, adding $25 \mathrm{~g}$ of PEG to $100 \mathrm{ml}$ water, followed by the addition of $10 \mathrm{~g}$ of sodium carbonate. The mixture was stirred thoroughly by a magnetic stirrer at $600 \mathrm{rpm}$ for 10 minutes. The temperature was raised to $40^{\circ} \mathrm{C}$ during mixing. Two separate layers of water and PEG were formed. In-situ polymerization was conducted in a three-neck reactor. A cold water condenser and a thermal probe were connected to the reactor to condense the formaldehyde fumes and maintain the required temperature during polymerization. An aque- ous prepolymer mixture containing 5\% SDS, 4\% PVA, 5\% Triton X100, and 5\% Resorcinol was added to the reactor. The PEG-water mixture was then added to the reactor and the mixture was stirred at $600 \mathrm{rpm}$ for 15 minutes. While stirring, $30 \mathrm{~g}$ of Urea was added to the reactor and two percent of Ammonium Chloride was added to the reaction. Thus an "oil-in-water system" was prepared, and a colloidal dispersion containing PCM was formed. The stirring speed was then reduced to $300 \mathrm{rpm}$ and the $\mathrm{pH}$ was lowered to $3.5-4.0$ by adding Citric acid. Finally, a stoichiometric molar amount of $37 \%$ Formaldehyde ( $15 \mathrm{~g})$ was added and the reaction was continued for 50 minutes at $40^{\circ} \mathrm{C}$. At the end of the reaction, the solution was cooled down to $25^{\circ} \mathrm{C}$. Microcapsules were separated out by filtering, and dried in the vacuum for 12 hours.

\section{Results and Discussion}

The unique nature of this study is in the in-situ polymerization, in an oil-water emulsion, with encapsulating water-immiscible liquids by the reaction of urea with formaldehyde at acidic $\mathrm{pH}$. The synthesis of urea-formaldehyde polymer takes place in two stages. In the first stage, urea is hydroxymethylolated by the addition of formaldehyde to the amino group of urea. This reaction is actually a series of reactions that leads to the formation of monomethylolurea, dimethylolurea, and trimethylolurea as illustrated in Figure 1.

The second stage of the Urea-formaldehyde resin synthesis consists of the condensation of methylolurea to a low molecular weight polymer. The increase in the molecular weight under acidic conditions, to produce higher molecular weight oligomers and polymers, is a combination of the following reactions: 1) Reaction between methylol and amino groups of the reacting molecules leading to methylene bridges between amino nitrogens; 2) Reaction of two methylol groups building methylene ether linkages; 3) Splitting out of formaldehyde from methylene ether linkages resulting in methylene linkages; 4) Reaction of methylol groups in which water and formaldehyde is separated out and further methylene linkages are obtained.

The schematic of the second stage reactions are described in Figure 2.

FTIR spectra of both neat PEG-600 and microencapsulate PEG-600 are shown in Figure 3. These two spectra showed very similar characteristic expected peaks at $3211 \mathrm{~cm}^{-1}, 1650 \mathrm{~cm}^{-1}$, and near $1400 \mathrm{~cm}^{-1}$. These peaks are attributed to $-\mathrm{NH},-\mathrm{C}=\mathrm{O}$ stretching vibrations and - $\mathrm{CH}$ bending, respectively. The spectra of the urea formaldehyde PEG microcapsule shows a strong band at 


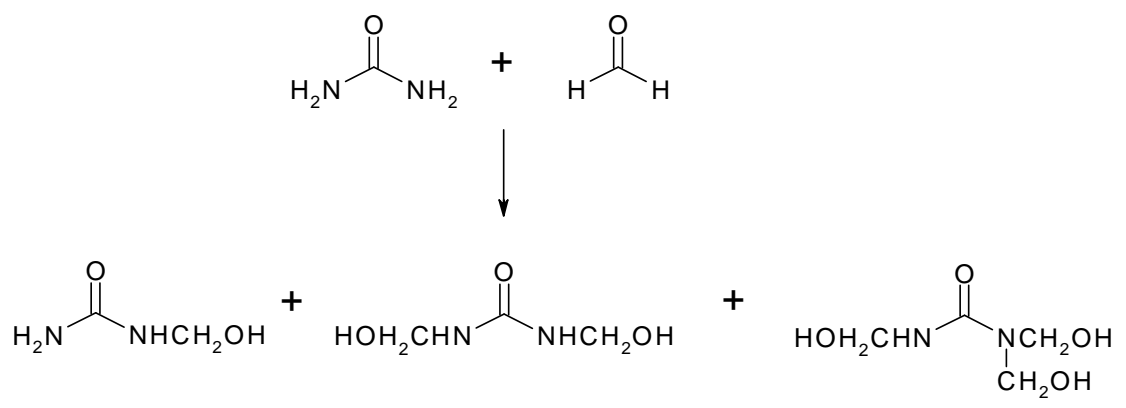

Figure 1. Scheme for the first step reaction.

(a)

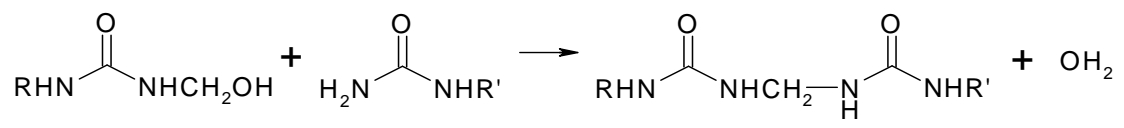

(b)

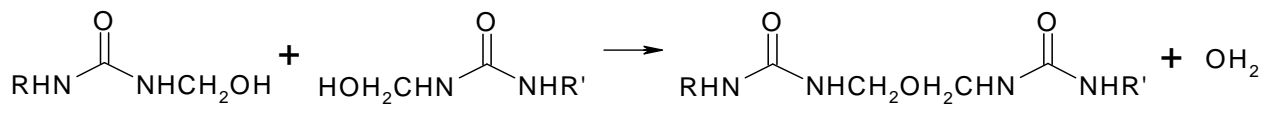

(c)

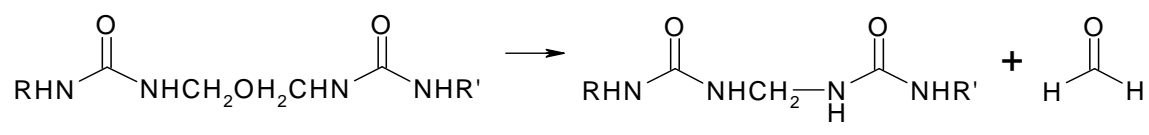

(d)

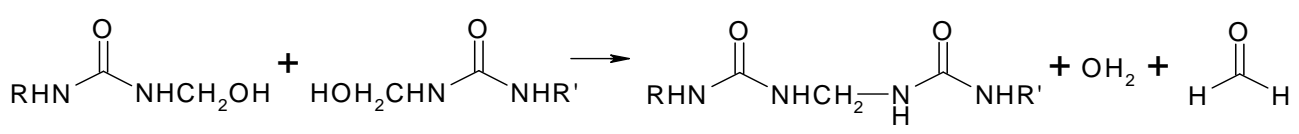

Figure 2. Scheme for the second stage reaction leading to urea + formaldehyde.

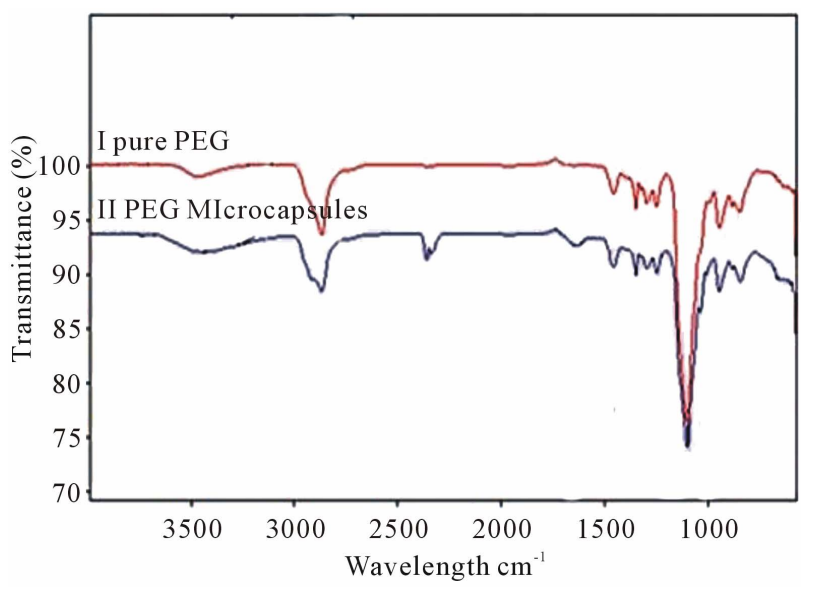

Figure 3. Illustrates the FTIR spectra of microencapsulated and neat PEG.

$3332 \mathrm{~cm}^{-1}$. This broad band is attributed to hydrogen bonded $\mathrm{N}-\mathrm{H}$ and $\mathrm{OH}$ vibrations. The strong peak at 1650 $\mathrm{cm}^{-1}$ has been assigned to $\mathrm{C}=\mathrm{O}$ stretching associated with the presence of a tertiary amide. The appearance of the $\mathrm{OH}$ band near $3360-3390 \mathrm{~cm}^{-1}$ is attributed to the hydrogen bonding. The analysis of FTIR spectra of the urea-formaldehyde microcapsule is consistent with the structure reported in Figure 3. It is observed that PEG encapsulated microcapsules exhibited strong $\mathrm{CH}_{2}$ stretching vibrations near $2800 \mathrm{~cm}^{-1}$, which is attributed to the presence of PEG. The thermogram of the heating, cooling and reheating of the PEG-microencapsules was examined using a DSC thermogram and illustrated in Figure 4. The microcapsules were cooled down to $-20^{\circ} \mathrm{C}$ and then heated up to $40^{\circ} \mathrm{C}$ at a rate of $10^{\circ} \mathrm{C}$ per minute. The melting temperature ( $\mathrm{Tm})$ of the microcapsules was found to be $21^{\circ} \mathrm{C}$ which was similar to that of the neat PEG 600. The heat storage capacity of the microcapsule was calculated to be $12.78 \mathrm{~J} / \mathrm{g}$. When the PCM microcapsules are heated, they absorb energy and convert from a solid state to a liquid state. This transition produces a temporary cooling effect in the clothing layer. If the PCM microcapsules are cooled down to below the recrystallization temperature $\left(12^{\circ} \mathrm{C}\right)$ of the PCM (PEG), causes an exothermic reaction, thus releasing heat to the 


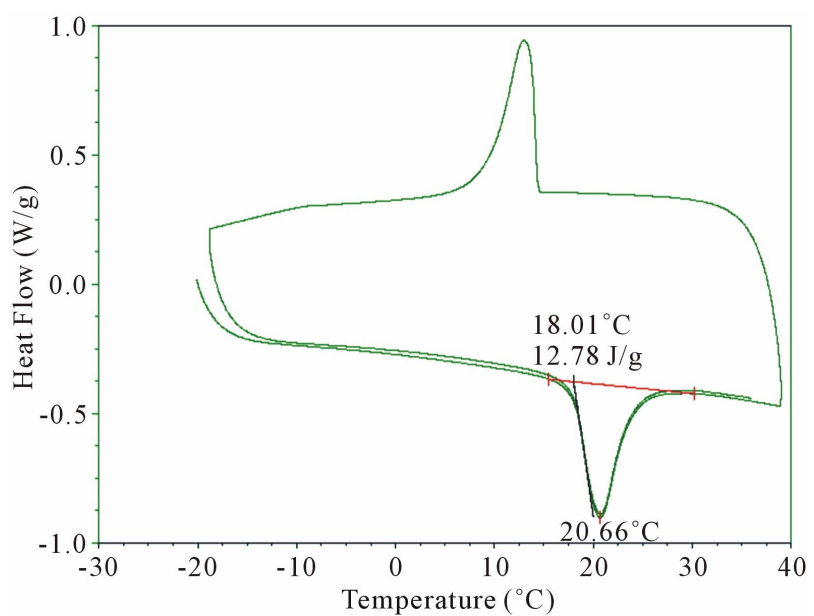

Figure 4. Shows DSC thermogram of the microencapsulated PEG-600.

fabric.

The SEM images of the microcapsules are shown in Figure 5. The microcapsules were somewhat uniform with an average diameter of $30 \mu \mathrm{m}$. They appeared to be round and spherical in shape with smooth surfaces. Microcapsules were coated on a $100 \%$ cotton scoured and bleached commercial fabric. The fabric was dip coated in a bath containing polyurethane (binder) and microcapsules. The ratio of microcapsules to binder was 20:80. The fabric was padded and cured at $80^{\circ} \mathrm{C}$. The coated specimen was tested for thermal resistivity on a Sweating Hot Plate containing micro-pores and was placed inside a controlled environmental chamber at $21^{\circ} \mathrm{C}$ and $65 \%$ humidity. The fabric specimen was placed on the sweating hot plate, with the coated side facing the hot plate. The heat releases from the fabric are monitored by a sensor placed $7 \mathrm{~mm}$ above the fabric while the hot plate is heated.

The thermal resistance of the untreated fabric was $0.034241 \mathrm{~m}^{2} \cdot{ }^{\circ} \mathrm{C} / \mathrm{w}$ while the PEG microcapsule treated fabric's thermal resistivity was 0.041023 . This implies that the sensor above the treated fabric detected $20 \%$ less heat than that of the untreated fabric, which is attributed to the absorption of heat by the microcapsules during the phase changing process, converting the PEG into a liquid phase. The Thermal resistance data are presented in Table 1.

\section{Conclusion}

In this investigation PEG-600 microcapsules were produced by an in-situ polymerization technique using ureaformaldehyde. FTIR analysis confirmed the presence of PEG within the microcapsules. Furthermore, DSC analysis showed that the energy storage capacity of the microcapsules was $12.78 \mathrm{~J} / \mathrm{g}$. The cooling effect of these
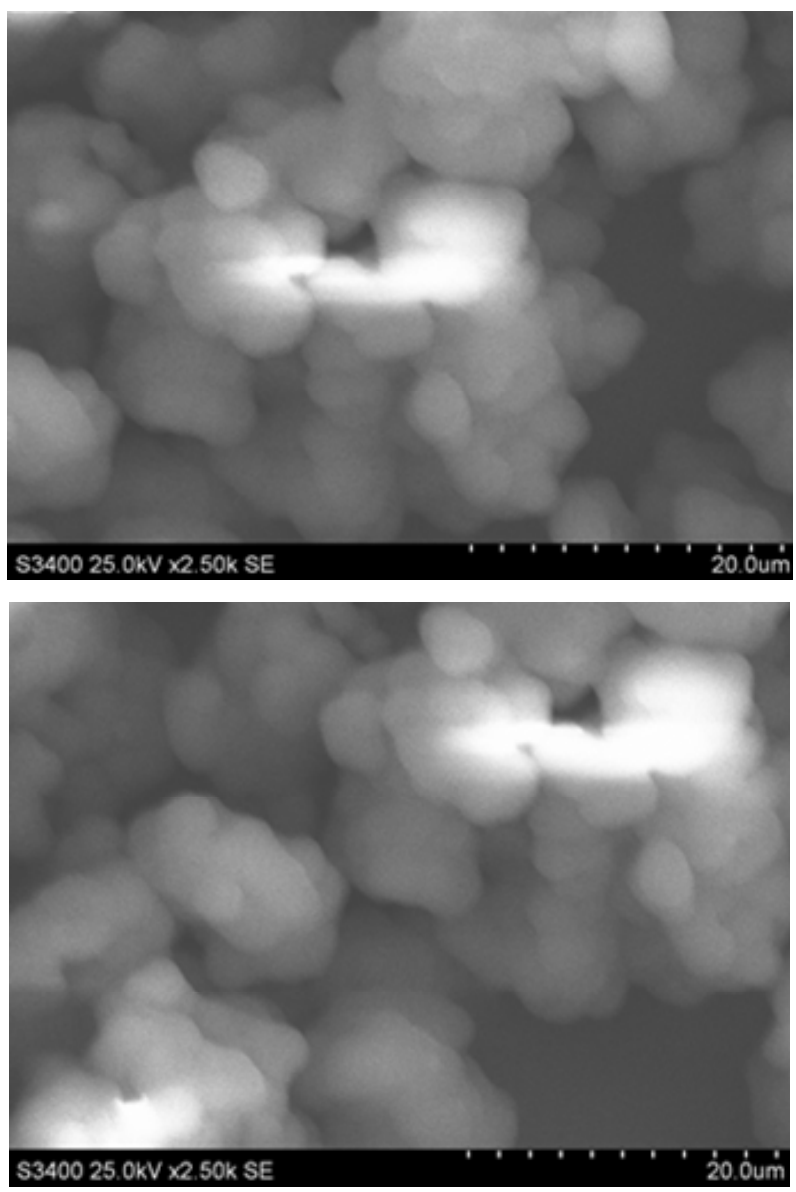

Figure 5. SEM images of the PCM microcapsules.

Table 1. Thermal resistivity of fabrics $\mathbf{m}^{2} \cdot{ }^{\circ} \mathrm{C} / \mathrm{w}$.

\begin{tabular}{cc}
\hline Uncoated Specimen & Coated Specimen \\
\hline 0.034241 & 0.0410234 \\
\hline
\end{tabular}

microcapsules on the textile fabric was also measured using a Sweating hot plate method. Further work using PEG with a higher molecular weight and microcapsule size distribution may prove to be useful.

\section{REFERENCES}

[1] M. O'Mahony and S. Braddock, "Sportstech: Revolutionary Fabrics, Fashion F," Thames \& Hudson, London, 2002.

[2] Y. Jun, C. Park, H. Shim and T. Kang, "Thermal Comfort Properties of Wearing Caps from Various Textiles," Textile Research Journal, Vol. 79, No. 2, 2009, pp. 179-189. doi:10.1177/0040517508093444

[3] S. Mondal, "Phase Change Material for Smart Textile: An Over View," Applied Thermal Engineering, Vol. 28, 2008, pp. 1536-1550. doi:10.1016/j.applthermaleng.2007.08.009

[4] E. Brown, M. Kessler, N. Sottos and S. White, "In Situ 
Poly(Urea-Formaldehyde) Microencapsulation of Dicyclopentadiene," Journal of Microencapsulation, Vol. 20, No. 6, 2003, pp. 719-730.

[5] G. Nelson, "Application of Microencapsulation in Textiles," International Journal of Pharmaceutics, Vol. 242, 2002, pp. 55-62. doi:10.1016/S0378-5173(02)00141-2

[6] F. Salaün, S. Bourbigot and P. Rumeau, "Development of Phase Change Materials in Clothing Part 1: Formulation of Microencapsulated Phase Change," Textile Research Journal, Vol. 80, No. 3, 2010, pp. 195-205. doi:10.1177/0040517509093436
[7] M. Taboada, T. Graber and L. Cisternas, "Sodium Carbonate Extractive Crystallization with Poly(Ethylene glycol) Equilibrium Data and Conceptual Process Design," Industrial Engineering Chemistry Research, Vol. 43, 2004, pp. 835-838. doi:10.1021/ie030692a

[8] A. Rochmadi, A. Prasetya and W. Hasokowati, "Mechanism of Microencapsulation with Urea-Formaldehyde Polymer," American Journal of Applied Sciences, Vol. 7, No. 6, 2010, pp. 739-745.

doi:10.3844/ajassp.2010.739.745 